\title{
Amplification of bacterial genomic DNA from all ascitic fluids with a highly sensitive polymerase chain reaction
}

\author{
HIRAYUKI ENOMOTO $^{1}$, SHIN-ICHI INOUE ${ }^{2}$, AKIO MATSUHISA ${ }^{2}$, YOSHINORI IWATA $^{1}$, NOBUHIRO AIZAWA ${ }^{1}$, \\ YOSHIYUKI SAKAI $^{1}$, RYO TAKATA ${ }^{1}$, NAOTO IKEDA ${ }^{1}$, KUNIHIRO HASEGAWA ${ }^{1}$, CHIKAGE NAKANO ${ }^{1}$, \\ TAKASHI NISHIMURA ${ }^{1}$, KAZUNORI YOH ${ }^{1}$, YUHO MIYAMOTO ${ }^{1}$, NORIKO ISHII ${ }^{1}$, YUKIHISA YURI ${ }^{1}$, \\ AKIO ISHII $^{1}$, TOMOYUKI TAKASHIMA ${ }^{1}$, HIROKI NISHIKAWA ${ }^{1}$, HIROKO IIJIMA ${ }^{1}$ and SHUHEI NISHIGUCHI $^{1}$ \\ ${ }^{1}$ Division of Hepatobiliary and Pancreatic Disease, Department of Internal Medicine, Hyogo College of Medicine, \\ Nishinomiya 663-8501; ${ }^{2}$ Research and Development Center, Fuso Pharmaceutical Industries, Ltd., Osaka 536-8523, Japan
}

Received February 11, 2017; Accepted April 6, 2018

DOI: $10.3892 / \mathrm{mmr} .2018 .9159$

\begin{abstract}
Due to varying positive rates of polymerase chain reaction (PCR) amplification, interpretation of conventional PCR results for non-infectious ascites remains problematic. The present study developed a highly sensitive PCR protocol and investigated the positive rate of PCR for the $16 \mathrm{~S}$ ribosomal (r)RNA gene in non-infectious ascites. Following the design of a new PCR primer pair for the 16S rRNA gene (800F and 1400R), the sequences of PCR products were analyzed and the lower limit for bacterial DNA detection evaluated. The positive rate of PCR for 16S rRNA gene in non-infectious ascites was also evaluated. PCR with the primer pair amplified the genomic DNA of $16 \mathrm{~S}$ rRNA genes of major disease-causing bacterial strains. Additionally, PCR with this primer pair provided highly sensitive detection of bacterial genomic DNA (lower limit, 0.1 pg of template DNA). When DNA samples isolated from ascites were used, the $16 \mathrm{~S}$ rRNA gene was amplified independently of the presence of bacterial infection. PCR products contained the genomic DNA fragments of multiple bacterial species. Bacterial genomic DNA can be amplified from all ascitic fluids using a highly sensitive PCR protocol. Careful attention is required to interpret the results based on simple amplification of $16 \mathrm{~S}$ rRNA gene with conventional PCR.
\end{abstract}

Correspondence to: Dr Hirayuki Enomoto, Division of Hepatobiliary and Pancreatic Disease, Department of Internal Medicine, Hyogo College of Medicine, 1-1 Mukogawa-cho, Nishinomiya 663-8501, Japan

E-mail: enomoto@hyo-med.ac.jp

Abbreviations: SBP, spontaneous bacterial peritonitis; PMN, polymorphonuclear neutrophil; ISH, in-situ hybridization; PCR, polymerase chain reaction; rRNA, ribosomal RNA

Key words: polymerase chain reaction, 16S ribosomal RNA gene, ascites, spontaneous bacterial peritonitis, bacterial translocation

\section{Introduction}

Spontaneous bacterial peritonitis (SBP) is one of the serious complications that can occur in cirrhotic patients and has high mortality and morbidity. Although the identification of pathogen(s) is essential for the management of infectious diseases, ascites fluid cultures often fail to provide positive results, even when using ascites samples from patients who develop clinical manifestations of SBP. Due to the necessity for early recognition and treatment, SBP is usually diagnosed on the basis of an absolute polymorphonuclear neutrophil (PMN) count in ascites with an optimal cut-off value of $\geq 250 / \mathrm{mm}^{3}$, even if the pathogen is not detected (1-4).

To overcome the difficulty experienced in obtaining direct evidence of bacterial infection in SBP ascites, an in-situ hybridization (ISH) method was recently developed and its potential clinical utility reported (5). Bacterial DNA detection and sequencing have been applied to the diagnosis of several infectious diseases. Molecular techniques can detect small amounts of bacterial DNA within a few h, and polymerase chain reaction (PCR)-based tests that target the bacterium-specific 16S-ribosomal (r)RNA gene would therefore provide a number of advantages. The highly conserved sequences of the gene allow broad-range detection of almost all bacterial species, while the hypervariable sequences can be used for pathogen-specific identification (6-9).

In the studies that have investigated ascites samples, PCR-based methods have demonstrated various positive rates and highly conserved sequences of $16 \mathrm{~S}$ rRNA have been detected in $\sim 30-60 \%$ of non-infectious ascites samples (10-14). However, with the detection of bacterial DNA in non-infectious clinical samples, serious criticisms of the contamination of PCR systems with bacterial DNA have been made (15-18). For instance, commercially available DNA polymerases can be contaminated with bacterial DNA, possibly as the products are generated as recombinant proteins in bacterial cells $(15,16)$. Other commercial products including the reaction tubes for PCR analysis have also been reported to contain contaminating DNA fragments $(17,18)$. However, if the amplification of $16 \mathrm{~S}$ rRNA gene is caused by contamination in these commercially available products, bacterial DNA should be amplified in all 
the samples tested. Previous studies have demonstrated that conventional PCR detects bacterial genomic DNA in 30-60\% of the non-SBP ascites samples tested (10-14). Therefore, it is also suggested that amplification of the 16S rRNA gene may reflect early detection of bacterial translocation in cirrhotic ascites.

Since previous studies have reported varying positive rates for PCR amplification, interpretation of PCR-based detection of the 16S rRNA gene in non-infectious ascites remains problematic. The present study developed a novel, highly sensitive PCR protocol and analyzed the amplification obtained using conventional PCR for the highly conserved sequences of the 16S rRNA gene.

\section{Patients and methods}

Study population. Cirrhotic patients with ascites who were admitted to Hyogo College of Medicine (Nishinomiya, Japan) between January 2010 and April 2013 were included in the present study. The study protocol conformed to the ethical guidelines of the 1975 Helsinki declaration and patients who agreed to the research use of ascites were enrolled following their informed consent. Cirrhosis was diagnosed on the basis of the histological results, clinical (laboratory or imaging) data, or both. Patients with any intra-abdominal, surgically treatable source of infection were excluded. Patients who received antibiotic treatment and patients with peritonitis carcinomatosa were also excluded from the analysis. The present study was approved by the Ethics Committee/Institutional Review Board of the Hyogo College of Medicine.

Paracentesis. Cirrhotic patients underwent diagnostic paracentesis under aseptic conditions using standard procedures for evaluation of the presence or absence of SBP. The routine biochemical variables and PMN count of the ascitic fluid were investigated. Ascites samples with a high PMN count $(\geq 250 / \mu \mathrm{l})$ and low PMN count $(<250 / \mu 1)$ were considered as SBP ascites and non-SBP ascites, respectively. Blood samples were also collected to perform routine clinical studies.

DNA extraction. Genomic DNA was isolated from the bacterial strains according to previously reported methods (5). The following bacterial strains were obtained from Microbe Division/Japan Collection of Microorganisms RIKEN BioResource Research Center (Tsukuba, Ibaraki, Japan): Escherichia coli (cat. no. JCM1649), Klebsiella pneumoniae subsp. pneumoniae (cat. no. JCM1662), Enterobacter cloacae subsp. cloacae (cat. no. JCM1232), Pseudomonas aeruginosa (cat. no. JCM5962), Bacteroides fragilis (cat. no. JCM11019), Enterococcusfaecalis (cat.no.JCM5803),Enterococcusfaecium (cat. no. JCM5804), Streptococcus pyogenes (cat. no. JCM5674) and Streptococcus agalactiae (cat. no. JCM5671). The following bacterial strains were obtained from American Type Culture Collection, (Manassas, VA, USA): Staphylococcus aureus (cat. no. ATCC12600), Staphylococcus epidermidis (cat. no. ATCC14990) and Streptococcus pneumoniae (cat. no. ATCC39938). DNA was isolated from ascitic fluids according to the methods described by Such et al (10). In brief, $200 \mu \mathrm{l}$ of an ascites sample was treated with an enzyme (lysozyme/proteinase K) containing buffer for $2 \mathrm{~h}$, and DNA was extracted using QIAamp Spin Columns (QIAamp DNA Mini kit; Qiagen GmbH, Hilden, Germany) according to the manufacturer's protocols (10).

Detection of bacterial DNA and DNA sequencing. To establish a new PCR protocol, the highly conserved sequences of the $16 \mathrm{~S}$ rRNA gene were analyzed. In the $16 \mathrm{~S}$ rRNA gene $(1,500 \mathrm{bp})$, it was identified that the sequences at positions $9,350,500,800,1,100$ and 1,400 were highly conserved. To increase the sensitivity of the PCR, various primer candidates whose sequences were GC-rich in the 3'-position were evaluated. These DNA sequence-related analyses were performed with commercially available software (DNASTAR Lasergene, Ver.7.1; DNASTAR, Inc., Madison, WI, USA). The primer pair 5'-CAAACAGGATTAGATACCCTGGTAGTCC-3' and 5'-TGTGTACAAGGCCCGGGAACGTATTCACCG-3' was designed on the basis of its specific amplification of the $16 \mathrm{~S}$ rRNA gene (800F-1400R; Fig. 1). Since two additional potential primer pairs [9F-500R: (5'-AGAGTTTGATCCTGGCTC AGGATGAACGCT-3' and 5'-TATTACCGCGGCTGCTGG CACGGAGTTAGC-3') and 350F-1100R: (5'-AGAGTTTGA TCCTGGCTCAGGATGAACGCT-3' and 5'-TATTACCGC GGCTGCTGGCACGGAGTTAGC-3')] failed in providing a specific amplification of 16S rRNA gene (data not shown), we used the primer pair shown in Fig. 1. The fragments of the 16S rRNA gene were amplified with a Gene Amp PCR system 9700 (Applied Biosystems; Thermo Fisher Scientific, Inc., Waltham, MA, USA) using the primer pair with the following conditions: $94^{\circ} \mathrm{C}$ for $30 \mathrm{sec}, 71^{\circ} \mathrm{C}$ or $55^{\circ} \mathrm{C}$ for $30 \mathrm{sec}$ and $72^{\circ} \mathrm{C}$ for $30 \mathrm{sec}$ for genomic DNA samples derived from bacterial strains; and $94^{\circ} \mathrm{C}$ for $30 \mathrm{sec}, 55^{\circ} \mathrm{C}$ for $30 \mathrm{sec}$, and $72^{\circ} \mathrm{C}$ for 30 for ascites-derived DNA. PCR conditions, including tested DNA templets and reaction cycles were determined according to the methods described by Such et al (10). The lower limit of detection of bacterial DNA was then determined. Bacterial genomic DNA was used at various concentrations (10, 1 and $0.1 \mathrm{pg}$ ) as templates for the PCR.

The present study used two types of DNA polymerases: AmpliTaq Gold LD (Applied Biosystems; Thermo Fisher Scientific, Inc.) and Prime STAR HS (Takara Bio, Inc., Otsu, Japan). All PCRs were performed according to the manufacturers' protocols. Commercially available RNase-free water (Takara Bio, Inc.) was used in all reactions. To obtain the DNA sequences of PCR products, the amplified products were purified and sequenced according to standard direct-sequencing techniques. Each sequence was subjected to analysis with the Basic Local Alignment Search Tool (BLAST) of GenBank to investigate the homology of the $16 \mathrm{~S}$ rRNA gene sequences (https://blast.ncbi.nlm.nih.gov/Blast.cgi).

\section{Results}

PCR primers for highly sensitive amplification of the $16 \mathrm{~S}$ rRNA gene. Among the three potential primer pairs that corresponded to the conserved sequences of the bacterial 16S rRNA gene, the primer pair described in the 'Patients and methods' section was successfully used for the amplification of DNA fragments from multiple bacterial strains and whether the amplified PCR products were consistent with the fragments of $16 \mathrm{~S}$ rRNA gene was investigated. Although the DNA 


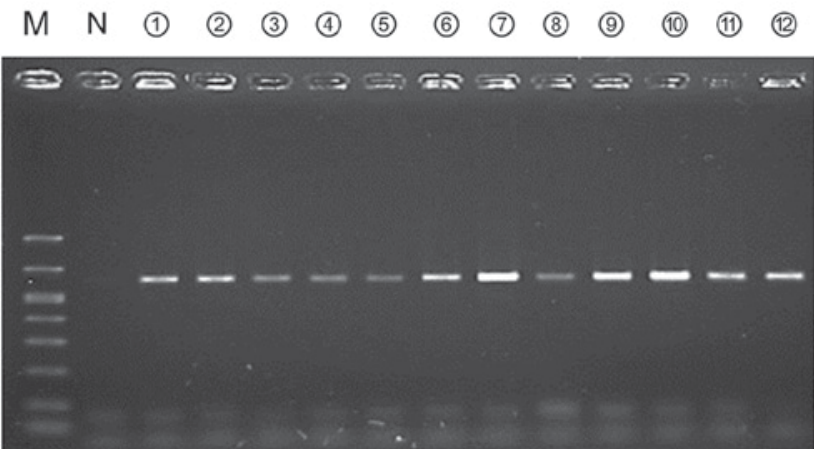

Figure 3. Amplification of the 16S rRNA gene using bacterial genomic DNA samples. PCR products were obtained from DNA samples of various bacterial strains. 1: Escherichia coli; 2: Klebsiella pneumoniae subsp. pneumoniae; 3: Enterobacter cloacae subsp. cloacae; 4: Pseudomonas aeruginosa; 5: Bacteroides fragilis; 6: Staphylococcus aureus; 7: Staphylococcus epidermidis; 8: Enterococcus faecalis; 9: Enterococcus faecium; 10: Streptococcus pneumoniae; 11: Streptococcus pyogenes; 12: Streptococcus agalactiae. PCR, polymerase chain reaction; rRNA, ribosomal RNA; N, Negative control; M, Marker.

Detection of bacterial DNA from non-SBP ascitic fluids. Sensitive PCR amplification of the 16S rRNA gene was established and then it was investigated whether the gene could be detected in non-infectious ascites. A total of 24 cirrhotic patients had sterile (non-infectious) ascites as defined in the 'Patients and methods' section. The baseline clinical characteristics of the patients with non-infectious acsitic fluids are shown in Table I. All patients had cirrhotic livers, and the Child-Pugh score was B in 7 patients and $\mathrm{C}$ in 17 patients. A total of 12 patients were diagnosed with non-viral cirrhosis and 12 with hepatitis $\mathrm{B}$ or $\mathrm{C}$ viral infection. The remaining 12 patients had non-viral cirrhosis that was associated with various liver diseases, including alcoholism, autoimmune hepatitis, primary biliary cholangitis and cryptogenic hepatitis (Table I).

Although the conditions used for PCR in the present study allowed for highly sensitive amplification of the $16 \mathrm{~S}$ rRNA gene, it was further investigated if conditions could be established for obtaining complete amplification of the gene from non-infectious ascites. When the results of the PCRs were carefully analyzed, the possibility that a PCR product was present in the negative control sample was noted, although the signal was very weak and uncertain (Fig. 3, lane N). To increase the sensitivity of the PCR, another DNA polymerase with higher efficacy of amplification was used (Prime STAR $\mathrm{HS}$ ) and the annealing temperature selected as $55^{\circ} \mathrm{C}$. It was confirmed that the $16 \mathrm{~S}$ rRNA target gene was more evidently amplified with the $0.1 \mathrm{pg}$ of the bacterial DNA template under this condition (Fig. 5) compared with the results in Fig. 4. It was then attempted to detect the 16S rRNA target gene from non-infectious ascites. On doing so, it was identified that the PCR products were amplified from all 24 non-SBP samples (Fig. 6). All PCR products had homologous sequences to the 16S rRNA gene; however, multi-peak signals were observed at numerous sequence points, and identification of specific pathogens was difficult, suggesting that each PCR product contained the genomic DNA fragments of polymicrobacteria (Fig. 7). These results suggested that sensitive amplification of the 16S rRNA gene was achieved with our PCR protocol and that bacterial DNA can be amplified from all samples independently of spontaneous bacterial infection or bacterial translocation in the abdominal cavity, since these conditions are considered to be a monobacterial infection in ascitic fluid (1-4).

\section{Discussion}

SBP is an infectious disease that develops in cirrhotic patients with ascites. Bacterial culture often fails to detect the pathogen. It is known that the $16 \mathrm{~S}$ rRNA gene is present in multiple copies in the genomes of bacterial pathogens and numerous bacterial species contain up to 7 copies of the gene (19). The presence of multiple copies can increase the possibility of detecting small numbers of pathogens, compared with assays performed for a single-copy gene. Therefore, PCR amplification of the bacterium-specific 16S rRNA gene is a useful method for investigating a broad range of bacterial species. However, it is unclear whether the PCR-based detection of the 16S rRNA gene is useful for determining the causative pathogen. A major problem is that the 16S rRNA gene can be amplified not only in SBP ascites but also in non-SBP sterile ascites, which makes it difficult to determine the clinical significance of this method.

Numerous commercially available recombinant DNA polymerases are generated in bacterial cells, and concerns about the presence of bacterial DNA in experimental items
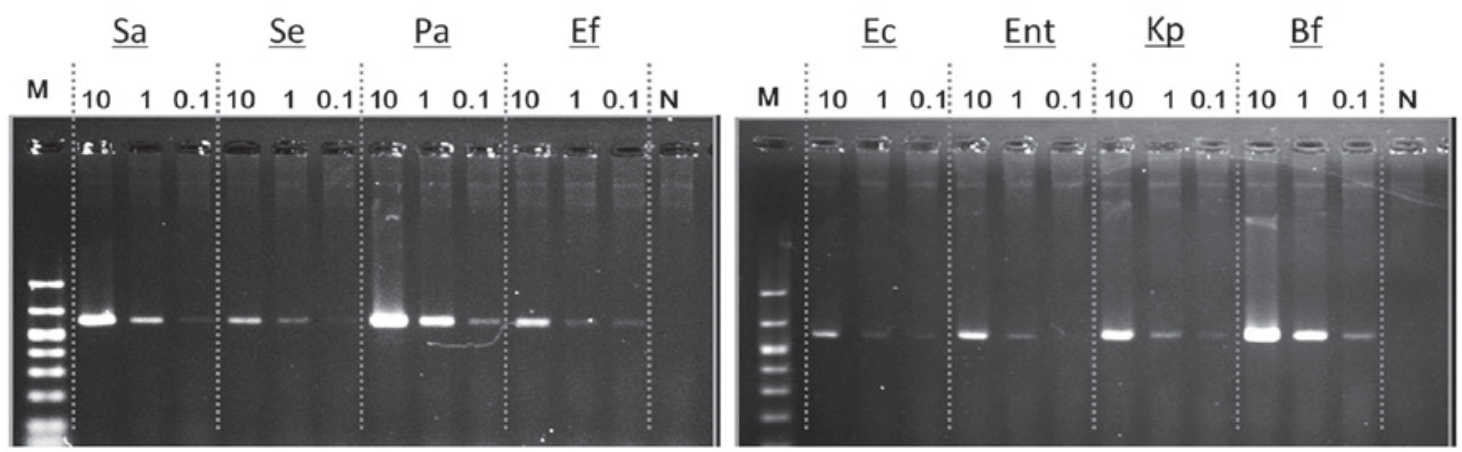

Figure 4. Amplification of the 16S rRNA gene using a small amount of bacterial DNA templates. With our PCR conditions, evidently detectable bands were obtained with only 0.1 pg of bacterial DNA template. rRNA, ribosomal RNA; Sa, Staphylococcus aureus; Se, Staphylococcus epidermidis; Pa, Pseudomonas aeruginosa; Ef, Enterococcus faecalis; Ec, Escherichia coli; Ent, Enterobacter cloacae subsp. cloacae; Kp, Klebsiella pneumoniae subsp. pneumoniae; Bf, Bacteroides fragilis; N, Negative control; M, Marker. 
Table I. Characteristics of the patients.

\begin{tabular}{lc}
\hline Parameter & Median value \\
\hline Age (years) & $59(50-82)$ \\
Sex & 17 \\
Male & 7 \\
Female & \\
Etiology & 4 \\
HBV & 8 \\
HCV & 12 \\
Non-viral & \\
Child-Pugh classification & 0 \\
A & 7 \\
B & 17 \\
C & $2.3(0.5-28.3)$ \\
Total bilirubin (mg/dl) & $2.7(2.0-4.3)$ \\
Albumin (g/dl) & $1.35(1.02-2.30)$ \\
PT-INR & \\
Hepatocellular carcinoma & 6 \\
Present & 18 \\
Absent & $(1-168)$ \\
PMN count of ascites (cells/ $\mu 1)$ & \\
\hline
\end{tabular}

HBV, hepatitis B; HCV, hepatitis C; PT-INR, prothrombin time-international normalized ratio; PMN, polymorphonuclear leukocytes. Numerical variables were expressed as the median values (range, min-max value).

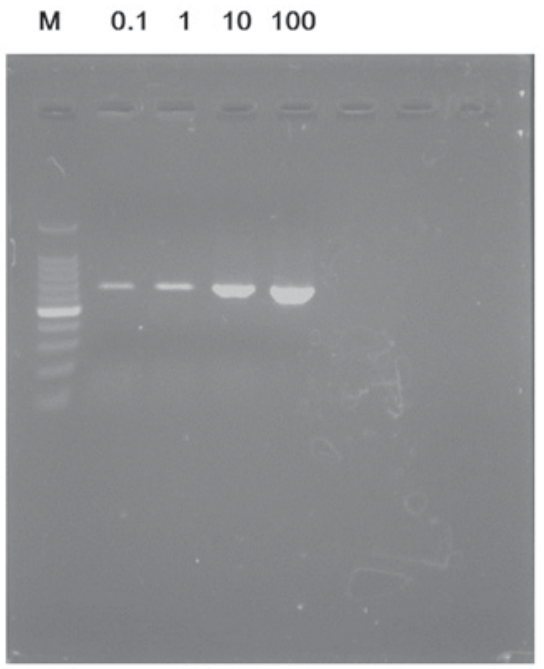

Figure 5. Amplification of 16S rRNA genes with higher efficacy of amplification. When DNA polymerase with higher efficacy of amplification (Prime STAR HS) was used and the annealing temperature of $55^{\circ} \mathrm{C}$ selected, the $16 \mathrm{~S}$ rRNA target gene was clearly amplified from the DNA template of Escherichia coli. rRNA, ribosomal RNA.

for PCR have been reported (15-17). Although several trials have been carried out to eliminate or reduce the amount of contaminating DNA (20-23), no method for absolute purification has been established (16). Therefore, a sensitive method may detect small amounts of contaminating bacterial genomic
DNA. However, if the amplified 16S rRNA gene from genomic DNA products of the clinical samples really represents the contaminated DNA, all PCRs should demonstrate positive results independent of bacterial infection. Nevertheless, previous studies have demonstrated that the PCR method can amplify 16S rRNA gene in fewer than $60 \%$ of sterile ascites samples (10-14). Therefore, it has been also suggested that amplification of the 16S rRNA gene is associated with early detection of bacterial translocation in cirrhotic ascites, since a small number of bacteria are presumed to invade the intraperitoneal cavity of cirrhotic patients with ascites via several pathways $(24,25)$. Conversely, it has also been reported that PCR detection of bacterial DNA in non-infectious ascites is not directly associated with the development of SBP (26), and the clinical implications of detecting the 16S rRNA gene with PCR remain unclear.

The present study attempted to amplify the $16 \mathrm{~S}$ rRNA gene in non-infectious ascites with newly-established conditions for PCR. Using this PCR protocol, a positive band could be obtained with $0.1 \mathrm{pg}$ of bacterial DNA templates. This limit is 100 times more sensitive than the previously reported PCR protocols, whose lower limits of bacterial DNA templates were $\sim 10 \mathrm{pg}(10,27,28)$. However, difficulty was experienced in determining the bacterial species with DNA sequencing due to the possible presence of DNA fragments corresponding to multiple microbial species (Fig. 7). Soriano et al (14) studied 20 non-infectious ascites samples and could amplify the $16 \mathrm{~S}$ rRNA gene in 12 samples. However, they succeeded in definitive bacterial identification only in 6 cases. They mentioned that the reason for the failure of the sequencing reaction could be low initial DNA concentration or the use of a mixture of amplification products that corresponded to multiple bacterial species. Tilburg et al (18) reported the probable contamination of a commercially available PCR Master Mix with bacterial DNA. They mentioned that the contamination was most likely caused by the use of compounds of animal origin due to the asymptomatic presence of several microorganisms in animals. As described above, although several studies have aimed to avoid bacterial DNA contamination of DNA polymerase (20-23), complete eradication of bacterial DNA is thought to be very difficult (16). The present study consistently demonstrated that a simple conventional PCR targeting the $16 \mathrm{~S}$ rRNA gene invites criticism with respect to the identification of the causative pathogen.

To confirm the results of the present study, PCR was repeatedly performed, including using different batch numbers of PCR reagents, 16S rRNA genes were amplified from all non-SBP samples. The results of the present study may reflect contamination of commercially available PCR systems with multiple bacterial species. The possibility that the PCR products reflect the presence of bacterial DNA due to bacterial translocation cannot be dismissed, but, taking into account previous studies that demonstrated the risk of contamination, the contaminating bacterial DNA fragments would be considered to be mainly responsible for the reproducible and complete amplification of bacterial DNA. It is therefore suggested that contamination with bacterial DNA would be a commonly observed inevitable problem when using highly sensitive conventional PCR to identify the pathogen. 


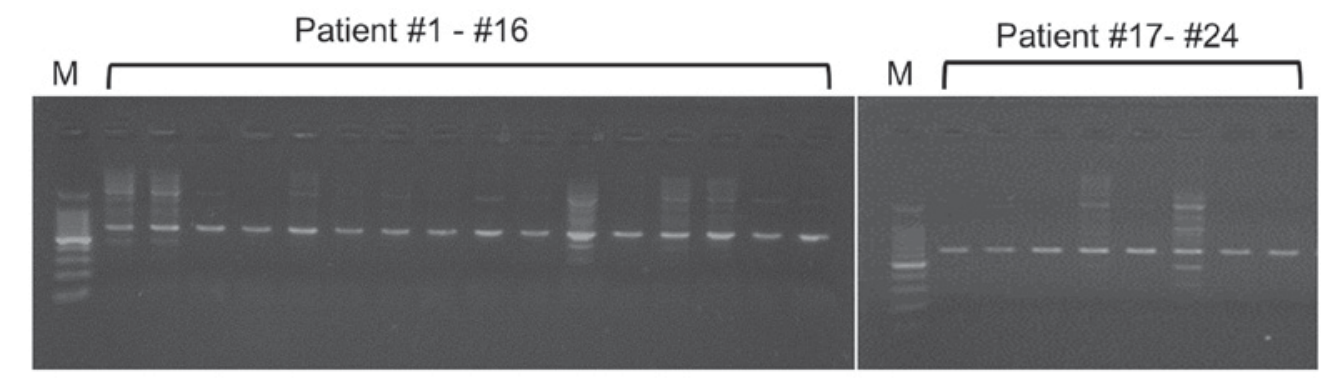

Figure 6. Results of PCRs with DNA samples of non-infectious ascites. PCR bands were obtained for all 24 ascites DNA samples, irrespective of the absence of bacterial infection. M, Marker; PCR, polymerase chain reaction.
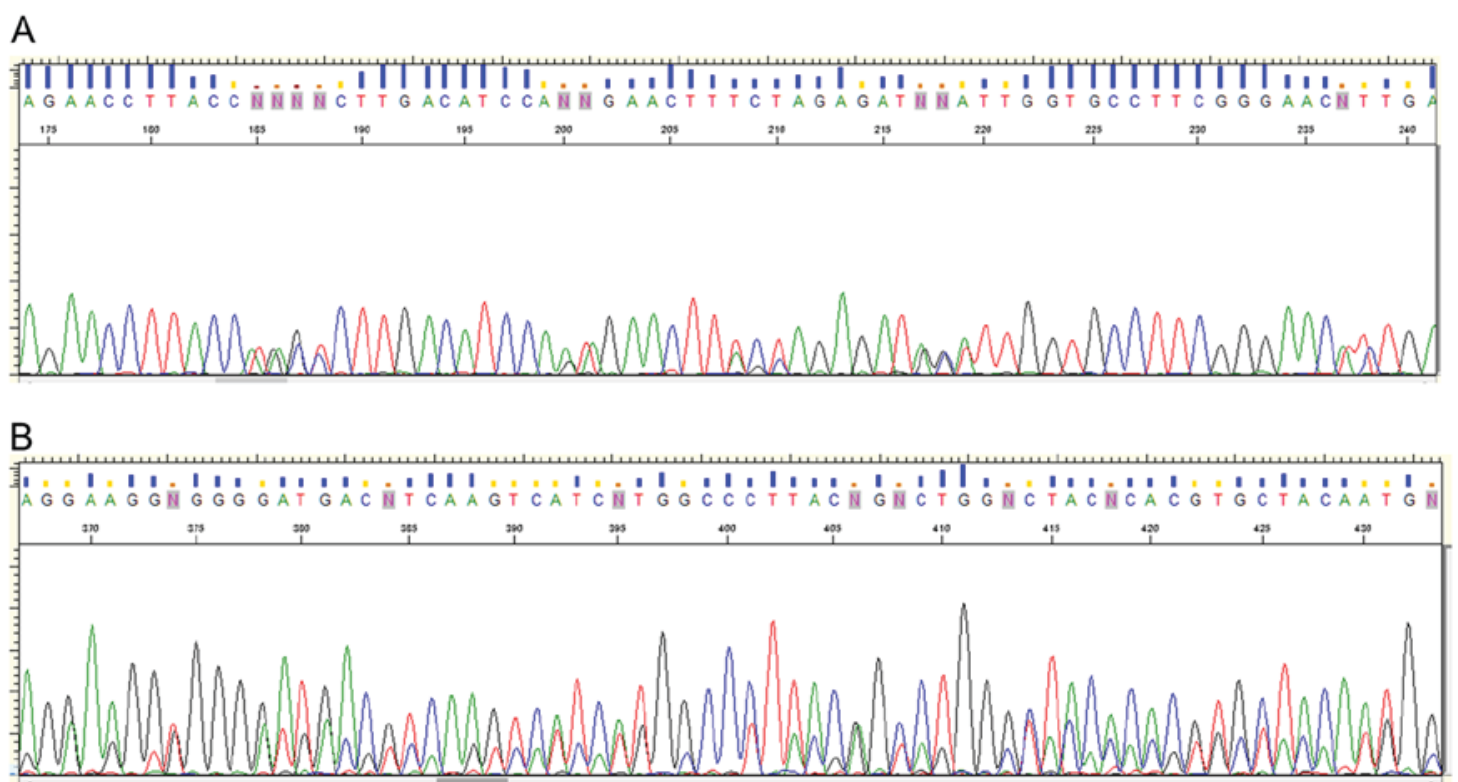

Figure 7. DNA sequences of PCR with samples of non-infectious ascites. (A) Although PCR products of a patient had homologous to the genomic sequences of 16S rRNA, multi-peak signals were observed at numerous sequence points and identification of specific pathogens was challenging. (B) PCR products with a sample of another patient also showed multi-peak signals at various sequence points.

Recently, in addition to the efforts on eliminating contaminating bacterial DNA, several new approaches have been reported to succeed in providing a clinical significance of $16 \mathrm{~S}$ rRNA gene amplification (29-32). For instance, the amount of $16 \mathrm{~S}$ rRNA gene has been shown to be associated with the prognosis of cirrhotic patients $(29,30)$. Additionally, advanced PCR-based methods for identifying bacterial pathogens, which cause SBP, have been also reported; excellent results were obtained with these assays, which should provide an improved approach for detecting pathogens $(31,32)$. To the best of the authors' knowledge, the present study is the first report regarding the $100 \%$ amplification of $16 \mathrm{~S}$ rRNA gene from non-infectious ascitic samples by a conventional PCR method. Its results suggest limitations of the simple PCR amplification and support the importance of the abovementioned recent superior techniques (29-32).

In conclusion, although recent advanced methods should demonstrate a clinical relevance, it is difficult to accurately detect the bacterial translocation in cirrhotic ascites with only a simple conventional PCR targeting the 16S rRNA gene. Careful attention is required to interpret the results based on simple amplification of 16S rRNA gene with conventional PCR.

\section{Acknowledgements}

The authors thank Ms. Kanazawa N., Ms. Deguchi N., Ms. Matsushita Y. and Ms. Fujii S. (Hyogo College of Medicine, Nishinomiya, Japan) for their technical assistance.

\section{Funding}

No funding was received.

\section{Availability of data and materials}

The analyzed datasets generated during the study are available from the corresponding author on reasonable request.

\section{Authors' contributions}

HE contributed to the study design, performed the experiments, analyzed the data and drafted the manuscript. SI-I and AM performed the experiments and edited the manuscript. NA, TT and $\mathrm{HN}$ contributed to the sample collection, data acquisition and data analysis. YI, YS, RT, NIk, KH, CN, TN, KY, YM, NIs, YY, 
$\mathrm{AI}$ and HI contributed to sample collection and data acquisition. SN contributed to the study design, analyzed the data and edited the manuscript. All authors were involved in the manuscript revision and approved the final version of the manuscript.

\section{Ethics approval and consent to participate}

The study protocol conformed to the ethical guidelines of the 1975 Helsinki declaration and patients who agreed to the research use of ascites were enrolled following their informed consent. The present study was approved by the Ethics Committee/Institutional Review Board of Hyogo College of Medicine.

\section{Consent for publication}

Patients gave informed written consent.

\section{Competing interests}

The authors declare that they have no competing interests.

\section{References}

1. Runyon BA; AASLD Practice Guidelines Committee: Management of adult patients with ascites due to cirrhosis: An update. Hepatology 49: 2087-2107, 2009.

2. Garcia-Tsao G and Lim JK; Members of Veterans Affairs Hepatitis C Resource Center Program: Management and treatment of patients with cirrhosis and portal hypertension: recommendations from the Department of Veterans Affairs Hepatitis C Resource Center Program and the National Hepatitis C Program. Am J Gastroenterol 104: 1802-1829, 2009.

3. European Association for the Study of the Liver: EASL clinical practice guidelines on the management of ascites, spontaneous bacterial peritonitis, and hepatorenal syndrome in cirrhosis J Hepatol 53: 397-417, 2010.

4. Wiest R, Krag A and Gerbes A: Spontaneous bacterial peritonitis: Recent guidelines and beyond. Gut 61: 297-310, 2012.

5. Enomoto $\mathrm{H}$, Inoue $\mathrm{S}$, Matsuhisa $\mathrm{A}$, Aizawa $\mathrm{N}$, Imanishi $\mathrm{H}$, Saito M, Iwata Y, Tanaka H, Ikeda N, Sakai Y, et al: Development of a new in situ hybridization method for the detection of global bacterial DNA to provide early evidence of a bacterial infection in spontaneous bacterial peritonitis. J Hepatol 56: 85-94, 2012.

6. Picard FJ and Bergeron MG: Rapid molecular theranostics in infectious diseases. Drug Discov Today 7: 1092-1101, 2002.

7. Baron EJ: Implications of new technology for infectious diseases practice. Clin Infect Dis 43: 1318-1323, 2006.

8. Woo PC, Lau SK, Teng JL, Tse H and Yuen KY: Then and now: Use of 16S rDNA gene sequencing for bacterial identification and discovery of novel bacteria in clinical microbiology laboratories. Clin Microbiol Infect 14: 908-934, 2008.

9. Sontakke S, Cadenas MB, Maggi RG, Diniz PP and Breitschwerdt EB: Use of broad range16S rDNA PCR in clinical microbiology. J Microbiol Methods 76: 217-225, 2009.

10. Such J, Francés R, Muñoz C, Zapater P, Casellas JA, Cifuentes A, Rodríguez-Valera F, Pascual S, Sola-Vera J, Carnicer F, et al: Detection and identification of bacterial DNA in patients with cirrhosis and culture-negative, nonneutrocytic ascites. Hepatology 36: 135-141, 2002.

11. Francés R, Zapater P, González-Navajas JM, Muñoz C, Caño R, Moreu R, Pascual S, Bellot P, Pérez-Mateo M and Such J: Bacterial DNA in patients with cirrhosis and noninfected ascites mimics the soluble immune response established in patients with spontaneous bacterial peritonitis. Hepatology 47: 978-985, 2008.

12. Sugihara T, Koda M, Maeda Y, Matono T, Nagahara T, Mandai M Ueki $\mathrm{M}$ and Murawaki Y: Rapid identification of bacterial species with bacterial DNA microarray in cirrhotic patients with spontaneous bacterial peritonitis. Inter Med 48: 3-10, 2009.

13. Bruns T, Sachse S, Straube E, Assefa S, Herrmann A, Hagel S, Lehmann $M$ and Stallmach A: Identification of bacterial DNA in neutrocytic and non-neutrocytic cirrhotic ascites by means of a multiplex polymerase chain reaction. Liver Int 29: 1206-1214, 2009.
14. Soriano G, Esparcia O, Montemayor M, Guarner-Argente C, Pericas R, Torras X, Calvo N, Román E, Navarro F, Guarner C and Coll P: Bacterial DNA in the diagnosis of spontaneous bacterial peritonitis. Aliment Pharmacol Ther 33: 275-284, 2011.

15. Corless CE, Guiver M, Borrow R, Edwards-Jones V, Kaczmarski EB and Fox AJ: Contamination and sensitivity issues with a real-time universal 16S rRNA PCR. J Clin Microbiol 38: 1747-1752, 2000.

16. Philipp S, Huemer HP, Irschick EU and Gassner C: Obstacles of multiplex real-time PCR for bacterial 16S rDNA: Primer specifity and DNA decontamination of Taq polymerase. Transfus Med Hemother 37: 21-28, 2010.

17. Evans GE, Murdoch DR, Anderson TP, Potter HC, George PM and Chambers ST: Contamination of Qiagen DNA extraction kits with Legionella DNA. J Clin Microbiol 41: 3452-3453, 2003.

18. Tilburg JJ, Nabuurs-Franssen MH, van Hannen EJ, Horrevorts AM, Melchers WJ and Klaassen CH: Contamination of commercial PCR master mix with DNA from Coxiella burnetii. J Clin Microbiol 48: 4634-4635, 2010.

19. Brosius J, Dull TJ, Sleeter DD and Noller HF: Gene organization and primary structure of a ribosomal RNA operon from Escherichia coli. J Mol Biol 148: 107-127, 1981.

20. Corless CE, Guiver M, Borrow R, Edwards-Jones V, Fox AJ and Kaczmarski EB: Simultaneous detection of Neisseria meningitidis, Haemophilus influenzae, and Streptococcus pneumoniae in suspected cases of meningitis and septicemia using real-time PCR. J Clin Microbiol 39: 1553-1558, 2001.

21. Carroll NM, Adamson P and Okhravi N: Elimination of bacterial DNA from Taq DNA polymerases by restriction endonuclease digestion. J Clin Microbiol 37: 3402-3404, 1999.

22. Klaschik S, Lehmann LE, Raadts A, Hoeft A and Stuber F: Comparison of different decontamination methods for reagents to detect low concentrations of bacterial 16S DNA by real-time-PCR. Mol Biotechnol 22: 231-242, 2002.

23. Silkie SS, Tolcher MP and Nelson KL: Reagent decontamination to eliminate false-positives in Escherichia coli qPCR. J Microbiol Methods 72: 275-282, 2008.

24. Benjamin J, Singla V, Arora I, Sood S and Joshi YK: Intestinal permeability and complications in liver cirrhosis: A prospective cohort study. Hepatol Res 43: 200-207, 2013.

25. Aberg F, Helenius-Hietala J, Meurman J and Isoniemi H: Association between dental infections and the clinical course of chronic liver disease. Hepatol Res 44: 349-353, 2014.

26. Zapater P, Francés R, González-Navajas JM, de la Hoz MA, Moreu R, Pascual S, Monfort D, Montoliu S, Vila C, Escudero A, et al: Serum and ascitic fluid bacterial DNA: A new independent prognostic factor in noninfected patients with cirrhosis. Hepatology 48: 1924-1931, 2008.

27. Hiramatsu K, Harada K, Tsuneyama K, Sasaki M, Fujita S, Hashimoto T, Kaneko S, Kobayashi K and Nakanuma Y: Amplification and sequence analysis of partial bacterial $16 \mathrm{~S}$ ribosomal RNA gene in gallbladder bile from patients with primary biliary cirrhosis. J Hepatol 33: 9-18, 2000.

28. Islam D, Bandholtz L, Nilsson J, Wigzell H, Christensson B, Agerberth B and Gudmundsson G: Downregulation of bactericidal peptides in enteric infections: A novel immune escape mechanism with bacterial DNA as a potential regulator. Nat Med 7: 180-185, 2001.

29. Hardick J, Won H, Jeng K, Hsieh YH, Gaydos CA, Rothman RE and Yang S: Identification of bacterial pathogens in ascitic fluids from patients with suspected spontaneous bacterial peritonitis by use of broad-range PCR (16S PCR) coupled with high-resolution melt analysis. J Clin Microbiol 50: 2428-2432, 2012.

30. Fagan KJ, Rogers GB, Melino M, Arthur DM, Costello ME, Morrison M, Powell EE and Irvine KM: Ascites bacterial burden and immune cell profile are associated with poor clinical outcomes in the absence of overt infection. PLoS One 10: e0120642, 2015.

31. Rogers GB, van der Gast CJ, Bruce KD, Marsh P, Collins JE, Sutton $\mathrm{J}$ and Wright $\mathrm{M}$ : Ascitic microbiota composition is correlated with clinical severity in cirrhosis with portal hypertension. PLoS One 8: e74884, 2013;

32. Krohn S, Böhm S, Engelmann C, Hartmann J, Brodzinski A, Chatzinotas A, Zeller K, Prywerek D, Fetzer I and Berg T: Application of qualitative and quantitative real-time PCR, direct sequencing, and terminal restriction fragment length polymorphism analysis for detection and identification of polymicrobial 16S rRNA genes in ascites. J Clin Microbiol 52: 1754-1757, 2014. 